\title{
Assessing the Potential of Stratospheric Balloons for Planetary Science
}

\author{
Tibor Kremic \\ NASA Glenn Research Center \\ 21000 Brookpark Road, M/S 142-5 \\ Cleveland, OH 44135 \\ 216-433-5356 \\ Tibor.Kremic@nasa.gov \\ Robert Landis \\ NASA Wallops Flight Facility \\ 34200 Fulton Street \\ Wallops, VA 23337 \\ 757-824-1641 \\ Rob.R.Landis@nasa.gov
}

\author{
Karl Hibbitts \\ JHU Applied Physics Lab \\ 11100 Johns Hopkins RD \\ Laurel, MD 20723 \\ 240-228-2834 \\ Karl.Hibbitts@jhuapl.edu \\ Keith Noll \\ NASA Goddard SFC \\ 8800 Greenbelt Road \\ Greenbelt, MD 20771 \\ 301-614-5968 \\ Keith.S.Noll@nasa.gov
}

\author{
Eliot Young \\ SW Research Institute \\ 1050 Walnut Street \\ Boulder, CO 80302 \\ 720-432-2333 \\ efy@boulder.swri.edu \\ Kevin Baines \\ NASA JPL \\ 4800 Oak Grove Drive \\ Pasadena, CA 91109 \\ 818-354-0481 \\ kbaines@jpl.nasa.gov
}

\begin{abstract}
Recent developments in high altitude balloon platform capabilities, specifically long duration flights in excess of 50 days at over $100,000 \mathrm{ft}$ and precision pointing with performance at the arc sec level or better have raised the question whether this platform can be utilized for high-value planetary science observations. In January of 2012 a workshop was held at NASA Glenn Research Center in Cleveland, Ohio to explore what planetary science can be achieved utilizing such a platform. Over 40 science concepts were identified by the scientists and engineers attending the workshop. Those ideas were captured and then posted to a public website for all interested planetary scientists to review and give their comments. The results of the workshop, and subsequent community review, have demonstrated that this platform appears to have potential for high-value science at very competitive costs. Given these positive results, the assessment process was extended to include 1) examining, in more detail, the requirements for the gondola platform and the mission scenarios 2) identifying technical challenges and 3) developing one or more platform concepts in enough fidelity to enable accurate estimating of development and mission costs. This paper provides a review of the assessment, a summary of the achievable science and the challenges to make that science a reality with this platform.
\end{abstract}

\section{TABLE OF CONTENTS}

1. INTRODUCTION .1

2. BALLOON WORKSHOP RESULTS.........................2

3. BALLOON STUDY .......................................................3

4. NEAR TERM PLANS.................................................7

5. SUMMARY .................................................................

REFERENCES........................................................

BIOGRAPHIES................................................................8

\section{INTRODUCTION}

Stratospheric balloons have been used to address NASA astrophysics, heliophysics, and other science questions for many years. Balloon platforms have enabled high value science for multiple disciplines and have done so in a cost effective manner. Balloon platforms, however, have not been commonly used for planetary science, which in this case refers to telescopic observations of our solar system's planets. This was due to the characteristics of high-altitude balloon payloads, namely a swinging and spinning platform, risk of damage during "landing" and limited observation windows and locations.

Recently NASA's Balloon Program Office (BPO) has demonstrated improvements in the limitation in these areas. Ultra long duration super pressure balloons have flown from Antarctic sites and stayed at desired altitudes for over 50 days and can carry payloads of significant size and mass. Figure 1 reflects potential mass and altitude options.

It is expected that flight of 100 days will be achievable in

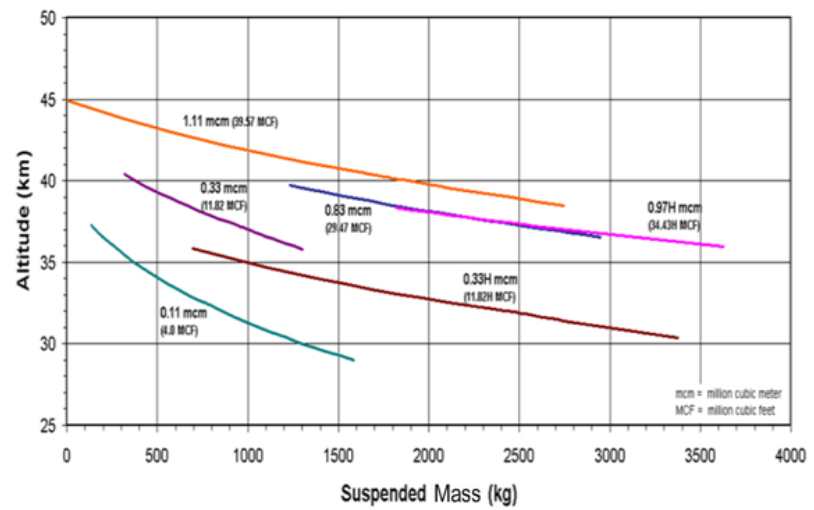

Figure 1 - Mass versus altitude for several zeropressure balloon options.

the near future. Perhaps more importantly, several missions such as SUNRISE and STO [1, 2, 3] have demonstrated sub arc-second pointing stability for minutes at a time. Given these two performance improvements, the question arose whether or not the platform is now a viable asset to achieve high-value planetary science.

A small team of scientists and engineers, led by NASA Glenn Research Center (GRC) with major contributions 
from the John's Hopkins University Applied Physics Laboratory (APL) and Southwest Research Institute (SwRI), began exploring this question. After a high-level survey of balloon platform capabilities and potential science, it was determined that a community workshop was warranted to effectively answer the question whether or not the platform can indeed achieve decadal class science and, if so, what that science would be.

The workshop verified the planetary science potential of this platform and set the stage for a study to better define the potential science contribution and the constraints, costs, and risks involved. This paper summarizes the results of the workshop and study to date.

\section{BALLOON WORKSHOP RESULTS}

\section{Workshop Purpose and Process}

The balloon workshop was held at NASA GRC in late January of 2011 with more than 70 participating scientists and engineers. The program goals of the workshop were:

(1) Determine if there is high-value planetary science that can be achieved from a stratospheric balloon platform.

(2) If yes, identify and document specific science concepts.

(3) Begin to identify the requirements, technical challenges and risks to developing a reusable platform suitable for the indentified science campaigns.

\section{Workshop Results}

During the workshop, key balloon features enabling science were identified for the various concepts. Platform mission and operational capabilities included:

(1) Continuous observations for days or longer or repeated observations for days or longer.

(2) Observations achievable above the telluric limitations of alternative ground based or atmospheric assets.

(3) Observations achievable beyond the operational and practical time allocation constraints of alternative assets (e.g. Hubble Space Telescope and SOFIA).

Breakout sessions by discipline were held and yielded more than 40 concepts for achievable planetary science. The concepts included a diverse set of science such as atmospheric dynamics at Venus, collecting interplanetary dust, characterizing small body composition, gas giant atmospheric observations, and others. A summary of the science ideas generated is provided in Table 1. No attempt was made to validate concept details or apply mission constraints during the workshop.

A website was established to make workshop presentations and results available to the public and broader planetary science community. Input and feedback are continuously
Table 1. Initial workshop science concepts.

\begin{tabular}{|c|c|}
\hline 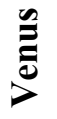 & $\begin{array}{l}\text { Venus Surface Thermal Emissivity } \\
\text { Lightning Detection on Venus } \\
\text { Venus Cloud Circulation }\end{array}$ \\
\hline$\underset{\Sigma}{\stackrel{n}{\Xi}}$ & $\begin{array}{l}\text { Water Cycle of Mars } \\
\text { Dust Cycle of Mars } \\
\text { Mars - Trace Gas Observations }\end{array}$ \\
\hline$\stackrel{\Xi}{\check{8}}$ & $\begin{array}{l}\text { Moon and Mercury non-mafic silicate composition } \\
\text { Temporal and Spatial Variance of Chemical Species in the } \\
\text { Exospheres of Moon and Mercury } \\
\text { Water Cycle on the Moon }\end{array}$ \\
\hline 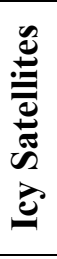 & $\begin{array}{l}\text { Methane Storm Cloud Evolution on Titan } \\
\text { Spectroscopy of Surface Ices on Triton, Pluto, and TNOs } \\
\text { Secular Vulcanism on Io } \\
\text { Discovery and Characterization of } \mathrm{CO}_{2} \text { on Airless Bodies } \\
\text { Enceladus OH Measurements } \\
\text { Light Curves of Materials for Titan, Triton, and others } \\
\text { Near Surface Methane on Titan }\end{array}$ \\
\hline 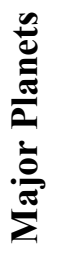 & $\begin{array}{l}\text { Red Absorber and Hydrocarbon Ices on Satellites } \\
\text { Ammonia Storm Cloud Evolution on Jupiter and Saturn } \\
\text { Methane Clouds on Uranus / Neptune } \\
\text { Aurorae Observations } \\
\text { Exogenic Water in Atmospheres } \\
\text { Mapping Eaves and Dynamics } \\
\text { Saturn Rings Observation }\end{array}$ \\
\hline 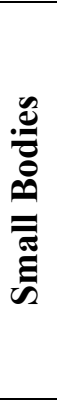 & $\begin{array}{l}\text { Survey and Characterization of Organics and Volatiles } \\
\text { Physical Properties of Asteroids } \\
\text { CO2 on Asteroids } \\
\text { Monitoring Comet / Transition Object Behavior } \\
\text { Population Compositional Characterization } \\
\text { Understand UV Variability in C-Type Asteroids } \\
\text { Space Weathering on S-Type Asteroids } \\
\text { Characterize Volatiles on TNOs } \\
\text { Search for OH Emission around Ceres } \\
\text { Faint Moving Objects } \\
\text { Interplanetary Dust Particles }\end{array}$ \\
\hline 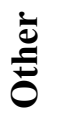 & $\begin{array}{l}\text { Instrument Validation } \\
\text { Rapid Response } \\
\text { Flight Mission Support }\end{array}$ \\
\hline
\end{tabular}

solicited. The website can be found at: http://spaceflightsystems.grc.nasa.gov/SSPO/SP/Balloon_Pl atform/.

Community responses received have been very positive and continue to highlight the potential of the stratospheric platform to achieve high value planetary science. In general, the specific concepts were found to be reasonable with given conditions for system architectures mission scenarios. There was general acknowledgement that the next step would be to apply real-world constraints to concepts, for example, currently the long duration flights are only available in Antarctica, which implies day time viewing conditions.

Given positive results of the workshop and community response, and the need to go deeper into validating the concepts and identifying technical hurdles and potential costs, the Planetary Science Division of NASA decided to initiate a small study to answer these needs. 


\section{BALLOON STUDY}

Study Purpose and Process

NASA Headquarters initiated a study in August, 2012 to evaluate the workshop concept ideas and systematically affirm science traceability to the Planetary Science's Decadal Survey. [4] Based on the achievable science, the study will develop high level requirements for the science payload, support systems, and mission operations (e.g. aperture, pointing stability, durations, etc.) and provide a recommendation for a baseline system to study in more detail to understand potential costs and risks. The recommended baseline concept will be evaluated by a team of balloon and engineering experts at NASA Glenn's COMPASS facility. The collaborative engineering team will develop an integrated system level point design and concept of operations to provide the required cost and risk assessments. The overall study process is shown in Figure 2. The status and results of the study will be presented to the planetary community through various venues including Assessment Group meetings, AGU and the 2012 LPSC.

\section{Science Traceability Results}

Results of the science review and decadal traceability indicated high correlation to NASA's strategic science goals. The study team systematically evaluated every "important question" for all categories within the survey for the potential of a balloon based asset to partially or fully address each question. Stratospheric balloon based systems could address or make progress on more than 20 percent of the science questions presented in the planetary decadal survey. Table 2 illustrates the potential contribution of a stratospheric balloon based platform to make science contributions for the various decadal survey science target categories.
Table 2. Potential science contribution traceability to decadal survey.

\begin{tabular}{|l|c|c|c|}
\hline \multicolumn{1}{|c|}{ Category } & $\begin{array}{c}\text { Total \# of DS } \\
\text { "Important } \\
\text { Questions" }\end{array}$ & $\begin{array}{c}\text { \# Answered or } \\
\text { significantly } \\
\text { addressed }\end{array}$ & $\begin{array}{c}\% \\
\text { Addressed }\end{array}$ \\
\hline Small Bodies & 23 & 10 & $43 \%$ \\
\hline Inner Planets & 39 & 11 & $28 \%$ \\
\hline Major Planets & 39 & 6 & $15 \%$ \\
\hline lcy Satellites & 75 & 12 & $16 \%$ \\
\hline Mars & 48 & 3 & $6 \%$ \\
\hline Total & 194 & 42 & $21 \%$ \\
\hline
\end{tabular}

Each decadal survey "important question" was vetted by several members of the science community. The complete list of questions and balloon based asset applicability is posted on the balloon platform website for review and comment. Two specific examples are provided in Table 3. Based on the overall results, a balloon based asset should allow significant progress at addressing the key questions over several categories and communities from small bodies to giant planets.

Examples of high science return per the decadal survey could include high spatial resolution NUV-NIR imaging of Venus with a 1-m aperture; responding to two priority questions under the objective "Determine how solar energy drives atmospheric circulation, cloud formation, and chemical cycles on Venus." Another example would be 2.55 micron spectroscopy of small bodies responding to five priority questions under the objective "Determine the composition, origin, and primordial distribution of volatiles and organic materials in the solar system."

Small body science appears to be particularly fruitful for a balloon born telescope. This is due to the nature of the questions and the ability of the balloon to observe faint objectives from a vantage point that is free from most atmospheric absorption and disturbances. Given current

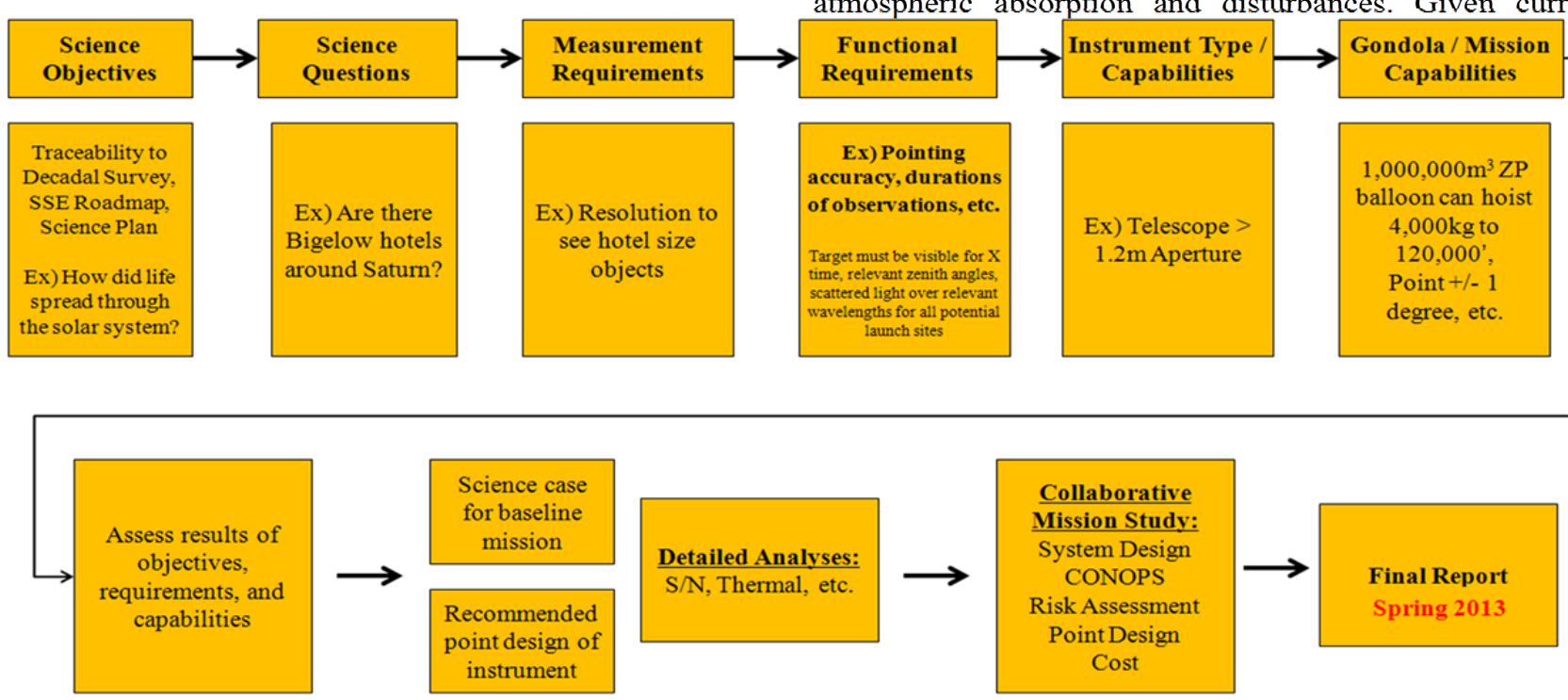

Figure 2 - Study flow to assess planetary science balloon asset viability. 
Table 3. Example science questions that can be at least partially addressed by a balloon based asset.

\begin{tabular}{|c|c|c|c|c|}
\hline Goals & Specific Objectives & $\begin{array}{c}\text { Important } \\
\text { Questions }\end{array}$ & $\begin{array}{c}\text { Possible } \\
\text { Measurement }\end{array}$ & Unique/Advantageous Balloon Observable \\
\hline $\begin{array}{c}\text { Understand } \\
\text { processes } \\
\text { that control } \\
\text { climates }\end{array}$ & $\begin{array}{c}\text { Determine how solar } \\
\text { energy drives } \\
\text { atmospheric } \\
\text { circulation, cloud } \\
\text { formation, and } \\
\text { chemical cycles }\end{array}$ & $\begin{array}{c}\text { How do the global } \\
\text { atmospheric } \\
\text { circulation patterns } \\
\text { of Venus differ } \\
\text { from those of Earth } \\
\text { and Mars? }\end{array}$ & $\begin{array}{c}\text { Single and multiband } \\
\text { NUV-NIR imaging. }\end{array}$ & $\begin{array}{c}\text { A. Diffraction-limited seeing at NUV-VNIR. } \\
\text { B. Stable photometry enables color measurements. }\end{array}$ \\
\hline $\begin{array}{c}\text { What does the } \\
\text { fatellites of } \\
\text { the outer } \\
\text { solar system } \\
\text { form and } \\
\text { evolve? }\end{array}$ & $\begin{array}{c}\text { Composition and } \\
\text { distribution of volatiles } \\
\text { uranian moons tell } \\
\text { us about the } \\
\text { evolution of small } \\
\text { to medium sized icy } \\
\text { satellites? }\end{array}$ & $\begin{array}{c}\text { Organics, ices, } \\
\text { volatiles - 2- 5 } \\
\text { micron } \\
\text { spectroscopy. }\end{array}$ & $\begin{array}{c}\text { A. Extremely low downwelling radiance and extremely } \\
\text { good (nearly 100 percent everywhere) atmospheric } \\
\text { transmission. Telluric CO2 80 percent transmissive. } \\
\text { Very long integration times (many minutes) and long } \\
\text { mission/observation durations (hours for individual } \\
\text { objects). }\end{array}$ \\
\hline
\end{tabular}

observations have the least to offer. However, there are still significant contributions that can be made due to the ability of the platform to see the whole disk at time intervals that capture data that an orbiting mission cannot collect due to orbit periodicity.

It should be noted that the study did not assign a value or seek to prioritize one decadal science question above another. It should also be noted that several flights may be required to address one question, and conversely a single flight may be able to address a number of the decadal survey questions.

\section{Requirements Development}

Following the identification of measurements required to address the science questions, the full traceability matrix was completed to include the instrument requirements and the derived balloon platform requirements to achieve sufficient data resolution. Table 4 builds on the two examples from Table 3 and provides the derived measurement, support system requirements, and mission operational requirements.

Additionally, the study team explored the marginal science that can be achieved through larger apertures, better pointing systems, wider observation bands, and longer flight durations. This process, along with the proven capabilities of the NASA Balloon Program Office (BPO), helped identify a "sweet spot" gondola and telescope architecture for a low risk system offering high value science. The

Table 4. Requirements derived from desired science measurements.

\begin{tabular}{|l|c|l|}
\hline \multicolumn{1}{|c|}{$\begin{array}{c}\text { Important } \\
\text { Questions }\end{array}$} & $\begin{array}{c}\text { Instrument } \\
\text { Requirements }\end{array}$ & \multicolumn{1}{c|}{ Mission Requirements } \\
\hline $\begin{array}{l}\text { How do the global } \\
\text { atmospheric } \\
\text { circulation patterns } \\
\text { of Venus differ from } \\
\text { those of Earth and } \\
\text { Mars? }\end{array}$ & $\begin{array}{c}\text { 1Hz calibrated } \\
\text { imaging. 2 band. }\end{array}$ & $\begin{array}{l}\text { Stability: 1/10 pixel. } \\
\text { Nighttime required } \\
\text { Several night duration } \\
1 \mathrm{~m} \text { aperture }\end{array}$ \\
\hline $\begin{array}{l}\text { What does the } \\
\text { diversity of the } \\
\text { uranium moons tell } \\
\text { us about the } \\
\text { evolution of small to } \\
\text { medium sized icy } \\
\text { satellites? }\end{array}$ & $\begin{array}{c}\text { Spatially unresolved } \\
\text { spectroscopy 2-5 } \\
\text { um, 10nm spectral } \\
\text { resolution. }\end{array}$ & $\begin{array}{l}1 \text { arc-sec IFOV. } \\
\text { RMS stability of 0.5”. Daytime } \\
\text { okay. } \\
1 \mathrm{~m} \text { aperture } \\
120,000 \mathrm{ft} \text { required } \\
\text { Minutes to hours per object. }\end{array}$ \\
\hline
\end{tabular}

recommended starting point for a higher fidelity system design include a $1-\mathrm{m}$ class aperture with at least 1 arc-sec pointing capability to make progress towards the previously identified science goals. Figures 3 through 5 depict metrics evaluated to understand the scientific return of fielding more

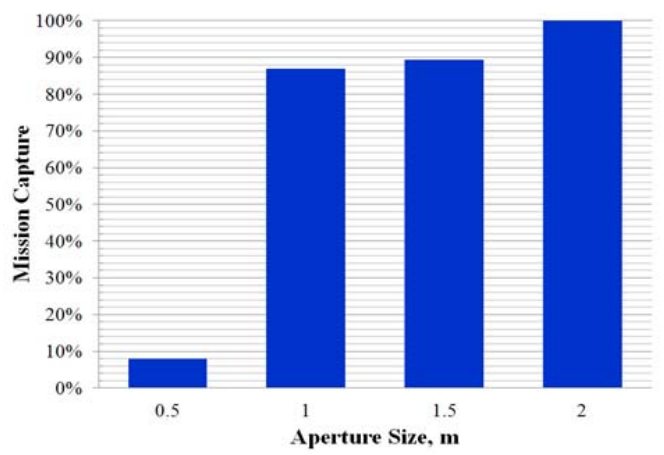

Figure 3 - Identified science mission capture versus telescope aperture.

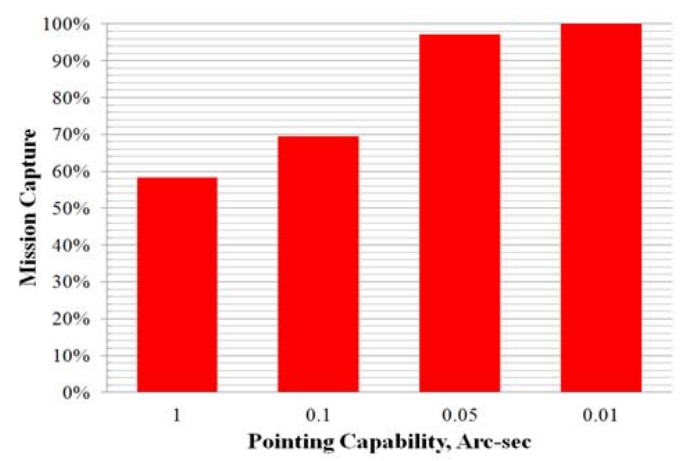

Figure 4 - Identified science mission capture versus pointing capability.

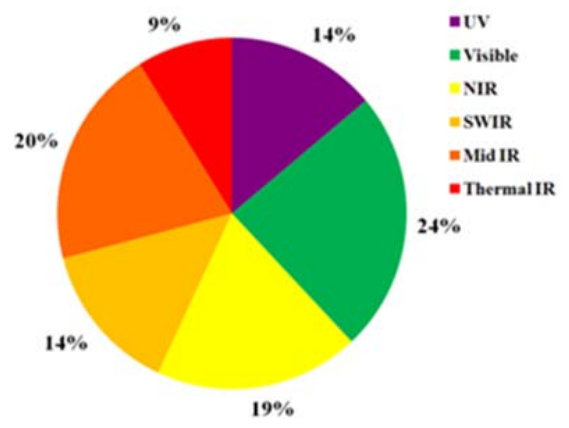

Figure 5 - Identified science mission capture versus observing spectrum. 
aggressive/capable assets.

\section{Comparison to Alternative Options}

To assess the payoff for investments in a balloon based asset, the science payoff must be compared to the existing capabilities. NASA already has access to world class assets for planetary science observations. Existing assets range from very large aperture ground based observatories, atmospheric observations enabled by SOFIA, and even the Hubble Space Telescope (HST). Alternatives have significant science capability, but lack some strengths that could be complemented by the use of a Balloon based asset; illustrated in Table 5.

Only balloons and SOFIA can conduct observations in the "water bands." Only balloons and HST have the capability of imaging visible targets at the 0.05 " level. Only balloons can conduct daytime mid-TR observations. Only balloons

Table 5. Comparison of balloon based observations to alternative assets.

\begin{tabular}{|c|l|l|l|l|}
\hline & SOFIA & HST & Ground & Balloon \\
\hline Time Allocation & & & & \\
\hline $\begin{array}{c}\text { Above telluric } \\
\text { absorption /background }\end{array}$ & & & & \\
\hline $\begin{array}{c}\text { Spatial Resolution / } \\
\text { Pointing }\end{array}$ & & & & \\
\hline Observing Efficiency & & & & \\
\hline Cost per Mission & & & & \\
\hline Aperture & & & & \\
\hline System Advantage: & High & & \\
\hline
\end{tabular}

can measure $\mathrm{CO}_{2}$ and have $10 \mathrm{x}$ lower downwelling radiance than SOFIA and near 100 percent transmission at other midIR wavelengths, and balloons have no measureable wavefront errors at $120,000 \mathrm{ft}$ and could perform diffraction limited visible imaging with a $2-\mathrm{m}$ aperture. SOFIA sees 15 times more atmosphere overhead than a balloon at 120,000 $\mathrm{ft}$, and the image seeing blur size from SOFIA is 3" or larger. The cost and duty cycle is also a critical factor; for perspective, a single 100-day balloon mission could provide 1,000 hours of dark time, more than ten times the annual solar system allotment on HST.

\section{Concept Design}

As a part of the larger study, the NASA GRC COMPASS team is developing mission concepts for near-term science return on a short duration flight while demonstrating systems and operations required for a long duration flight. The baseline short duration gondola is shown in Figure 6 . The gondola leverages several standard NASA balloon program office and Columbia Scientific Balloon Facility (CSBF) subsystems and design requirements including the solar pointing system, Wallops Arc-Second Pointer (WASP), primary batteries, ballast hopper, Support Instrument Package, etc.

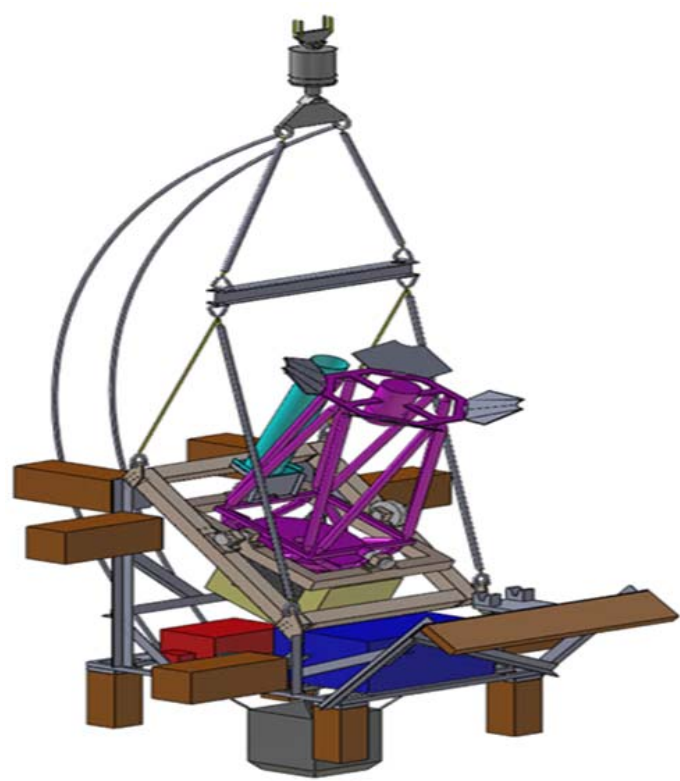

Figure 6 - Preliminary gondola concept.

\section{System Requirements}

The NASA Balloon Program Office and CSBF have been successfully flying stratospheric balloon science missions for decades. As noted above, the unique system requirement for planetary science objectives is primarily the arcsecond/sub-arcsecond pointing requirements; only demonstrated in recent years. Also, the pointing requirements must be met for both day and night observations. While arcsecond ponting is sufficient for many science objectives, to fully take advantage of diffraction limits of 0.1 "- 0.05 " (for 1- to 2-m apertures, respectively), a suspended telescope must be stabilized at the 0.05 "-0.02" level. The WASP is a set of nested gimbals that can keep large $(1500 \mathrm{lb}, 24 \mathrm{ft}$ long) telescope on target with rms pointing errors that are less than an arcsecond. The results from the first two WASP flights indicate that the dummy telescope payloads were stabilized at the 0.25 " level. [5] Reducing pointing errors from 1 " to 0.01 " is easily within the range of many fine steering mirrors, provided they can be driven by an accurate pointing signal.

The baseline system for meeting the pointing requirement is the WASP, and it is the primary structure from which the gondola is designed to accommodate. However, the WASP design as demonstrated is limited to apertures of $0.78 \mathrm{~m}$. A simple engineering change could accommodate a $0.91 \mathrm{~m}$ aperture, but larger apertures are currently beyond the manufacturing capability of WFF; mounting the primary mirror in front of the WASP would be required. Due to center-of-gravity restrictions, mounting the telescope in front of WASP can only be accommodated if the payload is sufficient low mass.

\section{Science Payload}

Based on the decadal survey science traceability, the baseline science payload is to accommodate narrow-field 
observations is the $0.3-5 \mu \mathrm{m}$ range with a $1-\mathrm{m}$ class primary aperture. A multi-channel Cassegrain telescope is the baseline approach to capture the spectral range. The primary difference between systems for Near/UV and IR is the platescale, and splitting the beam from the telescope into visible and IR channels with a dichroic would allow separate focal lengths to be implemented. The UV/Visible range would benefit from tighter pointing requirements, but at no penalty to the IR spectrograph. A notional optics bench is shown in Figure 7.

Zerodur primary and secondary mirrors with carbon fiber rubes will have very stable thermal expansion characteristics. An unlightweighted 1-m Zerodur primary

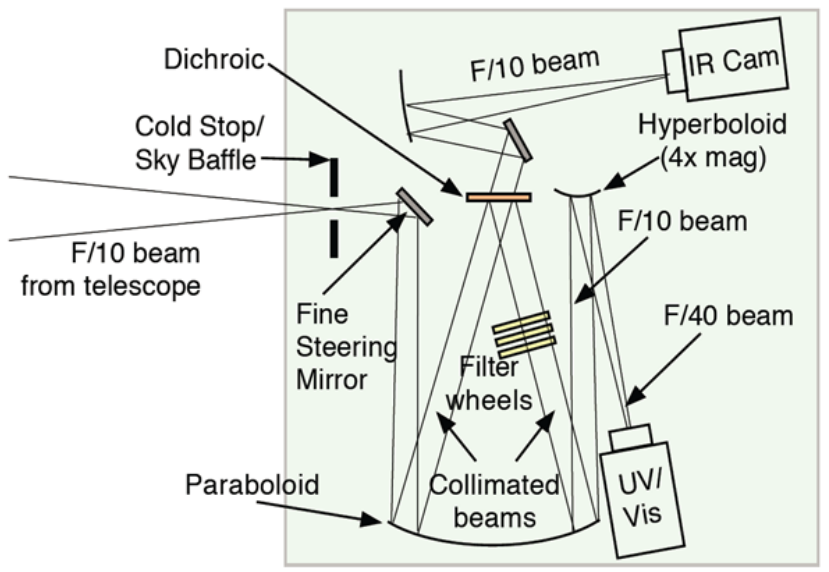

Figure 7 - Notional optics bench.

weighs approximately $350 \mathrm{lbs}$. The total $\mathrm{F} / 10$ Cassegrain Optical Tube Assembly (OTA) weighs approximately 515 lbs and is roughly 90 inches long. An enhanced aluminum option is the baseline coating for spectral range desired. The telescope specification and illustration are provided in Table 6 and Figure 8 respectively.

\section{Baseline Science}

The baseline flight is based on expected performance and

Table 6. Telescope elements specifications.

\begin{tabular}{|c|c|c|}
\hline Element & Dimensions & $\begin{array}{c}\text { Weight, } \\
\text { lb }\end{array}$ \\
\hline Primary Mirror & 40" Diameter, F/3 & 349 \\
\hline Secondary Mirror & $11.8 "$ D., Conic $=-3.44$ & 16.5 \\
\hline Primary Supports & & 21 \\
\hline Secondary Supports & & 28 \\
\hline Serrurier Truss & 3" D Composite Tubes & 50.7 \\
\hline Central Frame & $44 " x 44 " x 8 ", t=0.25 "$ & 48.5 \\
\hline Mirror Separation & $86.8 ”$ & \\
\hline Back Focal Distance & $24.0 "$ & \\
\hline Summary & F/10, 1-m Cassegrain & 514 \\
\hline
\end{tabular}

targets available in the fall of 2014. The preliminary schedule includes one hour of observations of the moon, Vesta, Jupiter (Galilean satellites), NEOs and 1.5 hours for Saturn during the day time science operations followed by 30 minutes for Ceres and Pluto observations and concluded

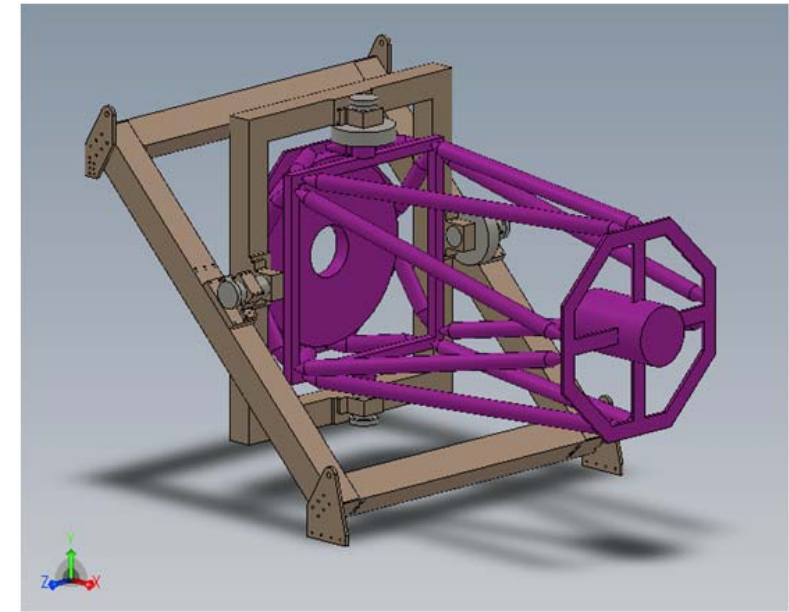

Figure 8 - Preliminary telescope mounted to WASP.

with two hours each of Uranus/moons and Neptune/moons observations. Altogether, the mission is expected to capture more than 150,000 images of the Galilean satellites and Jupiter, the Saturn, Uranian, and Neptunian systems, Ceres, Vesta, and Pluto. Observations include mapping atmospheric circulation patterns, searching for $\mathrm{OH}$ emission at Ceres, address prevalence of $\mathrm{CO}_{2}$, IR characterization of water, organics, and volatiles of airless bodies, and characterization of the spectral nature of hydroxyl on Vesta to improve our understanding of its origin. The mission float altitudes versus time are shown in Figure 9.

\section{System Summary}

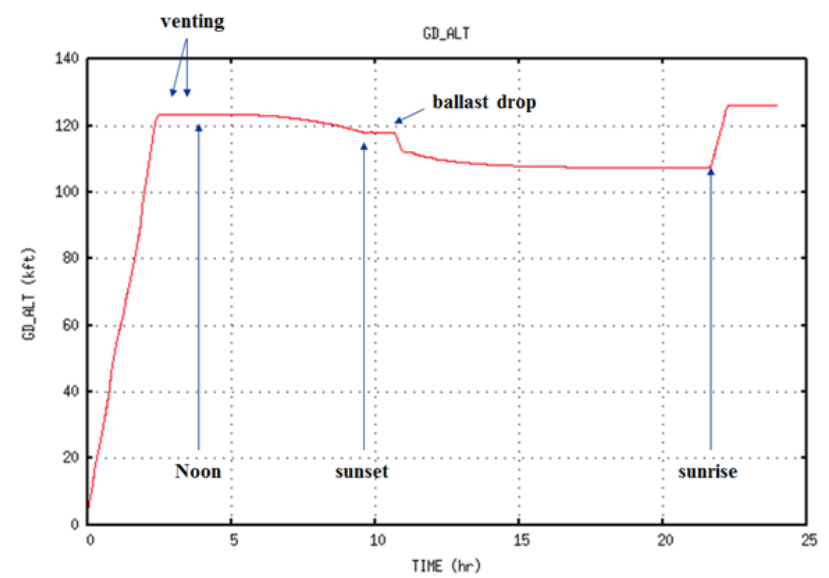

Figure 9 - Mission altitude vs. time.

The baseline concept is based on flying with the standard 29.47 million cubit foot balloon with a performance of 2722 $\mathrm{kg}$ at the desired float altitude. The total suspended mass with 30 percent margin is $1772 \mathrm{~kg}$, the additional balloon systems (parachute, termination system, etc.) has a mass of $418 \mathrm{~kg}$, for a total lift requirement of $2190 \mathrm{~kg} ; 20$ percent lower than the balloon's life capability. The integrated system is shown in Figure 10. While there is significant margin for growth, the baseline concept is too heavy to fly on a super-pressure balloon. Additional analysis will be completed to lightweight the payload system to accommodate a long duration super-pressure flight. 


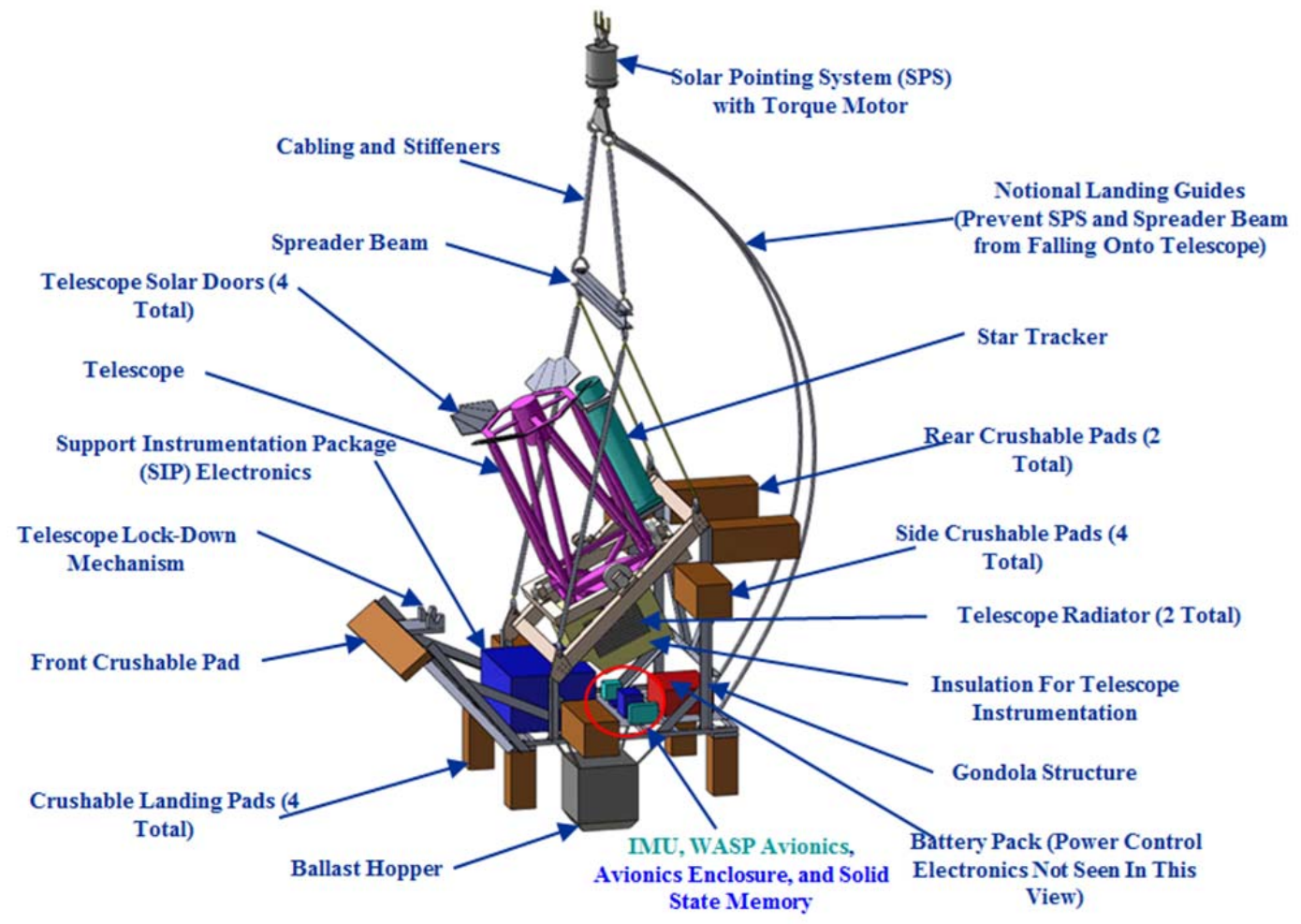

Figure 10 - Gondola concept design and subsystems.

\section{Near Term Plans}

The balloon based asset study is scheduled for completion in the spring of 2013. The first COMPASS level concept design was completed on November $2^{\text {nd }}$ and represents the study results at the time of publication. Throughout November, December and January, the study team will increase fidelity of the concept design with detailed system design including thermal desktop and finite element analysis of the integrated system. Thermal and thermal related structural concerns are anticipated for optical alignment and detector temperature requirements. The follow-on analyses will reduce risk on the concept design. A final design iteration, based on the higher fidelity assessment, will provide the recommended concept to the Planetary Science Division and be used as a benchmark for science return on investment. The design iterations will also evaluate lightweighted payload systems, solar power, and satellite communication necessary for long duration super-pressure flights.

\section{SUMMARY}

The cost and access to space based assets for planetary science limits the opportunities to meet the science objectives as provided by the Planetary Sciences Decadal Survey. There is insufficient funding to address all of the primary science goals at the wide range of targets within the next decade. Ground based assets, though highly valued, have limitations due to atmospheric attenuation. The NASA Balloon Program has successfully demonstrated the use of a balloon based platform for Earth Science, heliophysics, astrophysics, and technology demonstration. A study has been initiated to evaluate the potential for a balloon based asset to augment the planetary science assets and determine if a niche exists for high value science by offering higher performance than ground based assets, but at a fraction of the cost of space based alternatives. An interim science report indicates strong science potential and applicability across the solar system. A baseline concept yields significant science on a short duration mission using a zeropressure balloon. Design iterations, long-duration super pressure balloon concepts, and detailed cost analyses are underway. Study results are expected in the spring of 2013 and will be presented at the Lunar and Planetary Sciences Conference. Interim products will be posted to the website and community input is continuously solicited.

\section{REFERENCES}

[1] Barthol, Peter (ed), The SUNRISE Balloon-Borne Stratospheric Solar Observatory, 2011 ed. Springer; New York, May 23, 2011

[2] Barthol, Peter, "SUNRISE High Resolution Imaging and Polarimetry with a Balloon-Borne Stratospheric Solar Observatory,"

http://spaceflightsystems.grc.nasa.gov/SSPO/SP/Balloon Platform/documents/Balloon\%20Workshop/Presentations 2011_05_01_SUNRISE_in_brief_a.pdf

[3] Bernasconi, Pietro, "STO Mission Highlights \& GUSSTO Vision Concept," GUSSTO Mission Highlights/Plans, http://spaceflightsystems.grc.nasa.gov/SSPO/SP/Balloon_ Platform/agenda.html 
[4] National Research Council, "Vision and Voyages for Planetary Science in the Decade 2013-2022,” 2011.

[5] "Space quality data from balloon-borne telescopes: The High Altitude Lensing Observatory (HALO)", Astroparticle Physics, Vol. 38, pgs. 31-40, 10/2012.

\section{BIOGRAPHIES}

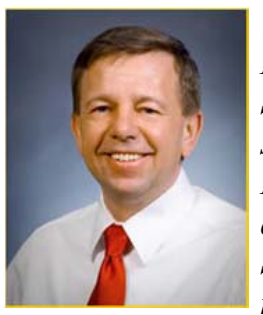

Tibor Kremic is currently working at NASA Glenn Research Center in the Science Project Office where he guides science related initiatives at the GRC. Formally he served on a detail as the assistant Division Director for Planetary Science where he contributed to the management of NASA planetary science program. Prior roles included management of organizations and project or program manager on a variety of NASA efforts, including NASA's In-Space Propulsion Technology Project. He also serves on a number of panels and teams focusing on science or space related technologies. Among the other duties he was the lead for the study discussed in this paper.

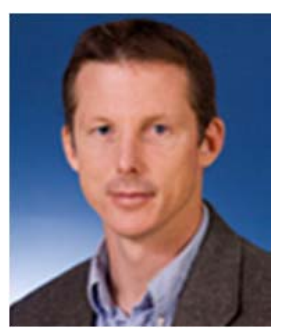

Charles A. Hibbitts received a B.A. in Physics from Cornell University in 1989. After serving in the military, he earned a degree in Geology from the University of New Mexico, and an MSc and PhD. in Geology and Geophysics at the University of Hawaii in 2001. His dissertation topic was understanding the surface compositions of the icy satellites of Jupiter by analyzing data returned by the Near Infrared Mapping Spectrometer aboard the Galileo spacecraft. Since then, Dr. Hibbitts has expanded his interests to other bodies of the solar system, including asteroids, the Moon, and the Earth.

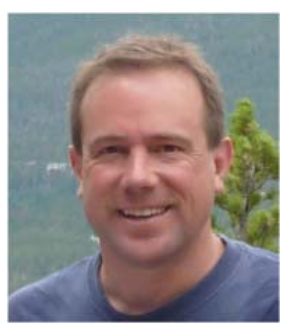

Eliot F. Young received an $A . B$.in Physics from Amherst College in 1984, an S.M. in Aeronautical Engineering from M.I.T. in 1987, an S.M. in Earth, Atmospheric and Planetary Science (EAPS) from M.I.T. in 1990, and an Sc.D. from M.I.T. (EAPS) in 1992. He is currently a Principal Scientist at Southwest Research Institute in Boulder, CO, in the Department of Space Studies. His current areas of study include the surfaces and atmospheres of Pluto, Triton, Eris and other large Trans-Neptunian Objects, as well as the distributions of aerosols and trace gases in Titan's atmosphere and the wind fields on Venus.

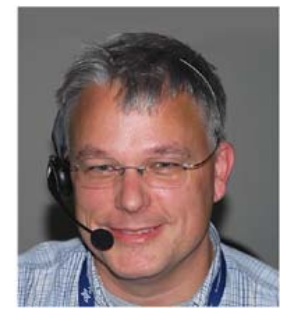

Rob R. Landis is currently a Program Officer within the Science Mission Directorate at NASA. Previously, $\mathrm{Mr}$. Landis was the Technical
Manager/Senior Engineer at the NASA Goddard Space Flight Center/Wallops Flight Facility. Before that he was the head of mission operations for the "robotic recon experiment" at the NASA Ames Research Center as well as part of the Lunar Surface Systems Project at the NASA Johnson Space Center. He previously worked at the Space Telescope Science Institute (STScI) on the Hubble Space Telescope, at the Goddard Space Flight Center on the Rossi $X$-ray Timing Explorer, and at the Jet Propulsion Laboratory on Cassini-Huygens and the Mars Exploration Rovers. Mr. Landis has a B.S. in astrophysics from Michigan State University and a M.S. in space studies from the University of North Dakota.

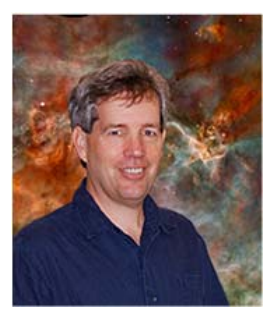

Keith Noll is the Chief of the Planetary Systems Laboratory at the NASA Goddard Space Flight Center. Prior to joining NASA in 2011 he spent 20 years at the Space Telescope Science Institute. He has published more than 90 refereed scientific papers on infrared spectroscopy of giant planet atmospheres and brown dwarfs, the ultraviolet reflectance of icy satellites, and, most recently, binary Kuiper Belt objects.

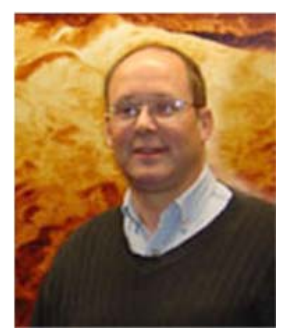

Kevin Baines, as both a Principal Scientist at Caltech/NASA/JPL and a Senior Scientist with the Space Science and Engineering Center at the University of Wisconsin-Madison, specializes in understanding the formation, evolution composition and structure of the atmospheres of the jovian planets and Venus. As a NASAnamed member of the Cassini Science Team, he is responsible for the acquisition and analysis of near-infrared images and spectra of Saturn's storms, planetary waves, and other meteorological features. He is also the leader of the American science team on ESA's Venus Express mission, and an associate team member of the New Horizons mission to Pluto. As a strong advocate of the scientific use of balloons, he is the Principal Investigator of the proposed Discovery VALOR long-duration ( 3 week) balloon mission to Venus which would ride the planet-wide jets-stream on a "World Tour" to provide fundamental insitu samples and insights into the planet's origins and exotic chemistry, dynamics, and circulation. 